\title{
Part 2: Preparing Entry-Level Occupational and Physical Therapy Students to Promote Healthy Lifestyles Emphasizing Healthy Eating with Individuals with Disabilities
}

Brooks C. Wingo

University of Alabama at Birmingham

Donald H. Lein

University of Alabama at Birmingham

Beth A. Barstow

$U A B$

Christopher A. Eidson

University of Alabama at Birmingham

Tara S. Pearce

University of Alabama at Birmingham

See next page for additional authors

Follow this and additional works at: https://encompass.eku.edu/jote

Part of the Occupational Therapy Commons

\section{Recommended Citation}

Wingo, B. C., Lein, D. H., Barstow, B. A., Eidson, C. A., Pearce, T. S., Malone, L. A., \& Morris, D. M. (2018). Part 2: Preparing EntryLevel Occupational and Physical Therapy Students to Promote Healthy Lifestyles Emphasizing Healthy Eating with Individuals with Disabilities. Journal of Occupational Therapy Education, 3 (1). https://doi.org/10.26681/jote.2019.030110 


\title{
Part 2: Preparing Entry-Level Occupational and Physical Therapy Students to Promote Healthy Lifestyles Emphasizing Healthy Eating with Individuals with Disabilities
}

\begin{abstract}
Rehabilitation professionals including occupational therapists (OT) and physical therapists (PT) are increasingly called upon to incorporate health promotion of lifestyle behaviors including physical activity and healthy eating into routine clinical care. While OTs and PTs may be comfortable promoting activity-related behaviors, many are less comfortable with nutrition behaviors. To address entry-level OT and PT students' perceived discomfort with discussing diet-related behaviors, faculty developed a healthy eating module for students to use during a community-based service learning program. The purpose of this paper is to describe the formative evaluation process of developing the healthy eating module, and to discuss results of a pilot trial of this module. The formative assessment of the healthy eating module consisted of four steps: focus groups with students, key informant interviews with community partners, expert panel round table, and expert panel review of materials. Students $(n=117)$ completed questionnaires at the end of the service learning program to assess how much they used the new resources, and how useful they found the resources. The final healthy eating module consisted of an on-line training session and a healthy eating toolkit, including resources for assessments, treatment activities and additional nutrition information. Mann-Whitney $U$ tests indicated that students who reported high use of materials found the resources significantly more helpful than those students who reported low use $(\mathrm{p}$
\end{abstract}

Keywords

Health promotion, nutrition behavior, service learning, entry-level curriculum

\section{Creative Commons License} (c) (1) $\Theta$

This work is licensed under a Creative Commons Attribution-Noncommercial-No Derivative Works 4.0 License.

\section{Authors}

Brooks C. Wingo, Donald H. Lein, Beth A. Barstow, Christopher A. Eidson, Tara S. Pearce, Laurie A. Malone, and David M. Morris 


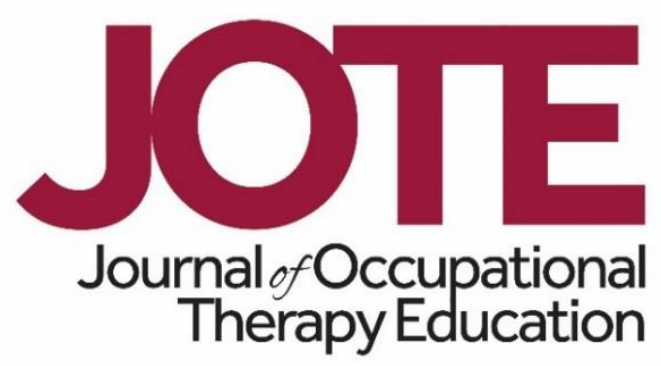

Volume 3, Issue 1

Part 2: Preparing Entry-Level Occupational and Physical Therapy Students to Promote Healthy Lifestyles Emphasizing Healthy Eating with Individuals with Disabilities

\author{
Brooks C. Wingo, PhD, Donald Lein, PT, PhD, \\ Beth Barstow, PhD, OTR/L, SCLV, FAOTA, Chris Eidson, MS, OTR/L, \\ Tara Pearce, PT, DHS, Laurie A. Malone, PhD, and David Morris, PT, PhD, FAPTA \\ University of Alabama at Birmingham \\ United States
}

\begin{abstract}
Rehabilitation professionals including occupational therapists (OT) and physical therapists (PT) are increasingly called upon to incorporate health promotion of lifestyle behaviors including physical activity and healthy eating into routine clinical care. While OTs and PTs may be comfortable promoting activity-related behaviors, many are less comfortable with nutrition behaviors. To address entry-level OT and PT students' perceived discomfort with discussing diet-related behaviors, faculty developed a healthy eating module for students to use during a community-based service learning program. The purpose of this paper is to describe the formative evaluation process of developing the healthy eating module, and to discuss results of a pilot trial of this module. The formative assessment of the healthy eating module consisted of four steps: focus groups with students, key informant interviews with community partners, expert panel round table, and expert panel review of materials. Students $(n=117)$ completed questionnaires at the end of the service learning program to assess how much they used the new resources, and how useful they found the resources. The final healthy eating module consisted of an on-line training session and a healthy eating toolkit, including resources for assessments, treatment activities and additional nutrition information. Mann-Whitney $U$ tests indicated that students who reported high use of materials found the resources significantly more helpful than those students who reported low use $(p<.001)$. Multi-step evaluation involving multiple stakeholders was helpful in creating the new healthy eating module and the pilot study revealed that revisions should focus on increasing student use of the materials.
\end{abstract}




\section{INTRODUCTION}

Increased rates of chronic diseases over the last three decades have led to calls to integrate health promotion into routine clinical practice for many healthcare professions. Health promotion activities focused on screening and addressing lifestyle behaviors including physical inactivity, poor diet, and smoking are now included in the clinical care guidelines for many disciplines, including occupational therapy (OT) and physical therapy (PT; American Physical Therapy Association, 2015; Jensen et al., 2014; KrisEtherton et al., 2014; Lichtenstein et al., 2006; Scaffa, Van Slyke, \& Brownson, 2008). A number of studies also report that patients are amenable to discussions of lifestyle behaviors initiated by their healthcare providers, and may report higher perceived quality of care when providers have these discussions with their patients (Jackson, Krishnan, Meccone, Ockene, \& Rubenfire, 2010; Pool et al., 2014; Rose, Poynter, Anderson, Noar, \& Conigliaro, 2013).

Despite the acknowledged need for health promotion activities in clinical care, and patients' perceived openness to these discussions, integration of these activities into routine clinical care has been slow. Among the many reported barriers to integrating health promotion, lack of knowledge and/or training in lifestyle behaviors, and specifically dietary behaviors, is a commonly cited barrier that may be especially salient for rehabilitation professionals (Bezner, 2015; Snodgrass et al., 2016; Walkeden \& Walker, 2015). While OTs and PTs have reported comfort with discussing physical activity, and to some extent smoking, they feel less comfortable discussing healthy eating behaviors or offering advice on improving dietary behaviors. In their report of a qualitative inquiry of acute care PTs, Walkeden and Walker (2015) reported that while most participants believed health promotion was within the scope of their practice, many noted that the aspects of health behaviors that should be addressed by PTs included exercise and smoking. Participants noted feeling most comfortable discussing exercise, while reporting that they felt less knowledgeable about how to discuss dietary habits, and suggested mandatory trainings to update staff on how to address health behaviors such as diet. This lack of perceived knowledge highlights an opportunity to increase entry-level healthcare providers' comfort with addressing heath behaviors by broadening the scope of entry-level OT and PT programs to include curriculum dedicated to key lifestyle behaviors such as dietary habits.

To ensure new professionals are able to provide health promotion services, accreditation standards for both OT and PT entry-level professional education programs mandate that occupational and physical therapy students have entry-level knowledge and skills to promote healthy behavior including nutrition optimization as part of their usual care (Accreditation Council for Occupational Therapy Education [ACOTE], 2018; Commission on Accreditation in Physical Therapy Education [CAPTE], 2016). To address these accreditation standards, faculty members in the University of Alabama at Birmingham (UAB) Departments of Occupational Therapy, Physical Therapy, and Human Studies (kinesiology and community health) collaborated with community partners to conduct a service learning activity (SLA) based on the I Can Do It, You Can Do It Program (ICDI). Developed by the President's Council on Fitness, Sports, and Nutrition, ICDI is a structured community health program where individuals without 
disabilities (mentors) are partnered with individuals with disabilities (mentees) to enhance physical activity, promote healthy eating, and encourage community participation (United States [US] Department of Health and Human Services, 2013a; US Department of Health and Human Services, 2013b). Individuals with physical and cognitive disabilities are at increased risk of chronic diseases compared to people without disabilities, highlighting the importance of rehabilitation professionals including OTs and PTs to be confident in addressing lifestyle behaviors with these groups (Liou, Pi-Sunyer, \& Laferrere, 2005; Centers for Disease Control and Prevention, 2002; Weil et al., 2002).

Student feedback from the initial ICDI program implementation in 2015 indicated that students believed they did well with engaging their mentees to encourage greater physical activity but overwhelmingly noted that they felt unprepared to discuss eating behaviors, and many felt it was outside the scope of OT and PT disciplines to have these conversations with clients. As a result, faculty of the ICDI program at UAB undertook a formal evaluation and revision process to address student perceptions of the role of OT, PT, and exercise science providers in promoting healthy eating behaviors with clients, and their level of knowledge of assessing and discussing healthy eating with clients. The purpose of this paper is to describe the formative evaluation process of developing the revised healthy eating module of ICDI at UAB, and to discuss results of a pilot trial of this module.

\section{METHODOLOGY}

\section{ICDI at UAB}

Full details of the ICDI program at UAB have been published previously (Wingo et al., 2019). In brief, the program is conducted as part of larger health promotion classes which are required coursework for second-year students in the Masters of Science in Occupational Therapy (MSOT) and Doctor of Physical Therapy (DPT) programs, and as a part of an elective course on adaptive physical activity for undergraduate students in the Department of Human Studies. In total, the 2015 ICDI interprofessional program included 6 faculty coordinators, 131 UAB students, and 68 mentees with disabilities. In 2016, a fourth community partner, ARC of Jefferson County, was added. Six faculty coordinators, 127 UAB students and 90 mentees participated in 2016. In addition, 25 dietetic interns from the Department of Nutrition at UAB were added as consultants for the 2016 mentors concerning healthy eating recommendations.

Students had access to the national ICDI program resources, which included a mentor manual and program website (US Department of Health and Human Services, 2013a; US Department of Health and Human Services, 2013b). Additionally, the ICDI program faculty at UAB developed five collaborative education sessions to prepare students for their mentoring tasks. These sessions included the following modules: orientation to ICDI, adaptive physical activity, healthy eating, goal-setting and communication, and sensory and cognitive impairment. Students worked in interdisciplinary groups of 3 (mentor groups), to mentor 1-2 mentees from the community partners. Throughout the one-semester program, mentor groups met with their mentees weekly for 60-90 
minutes. Each mentor group was required to conduct baseline assessments of eating behaviors and physical activity with each mentee, set appropriate long-term and shortterm goals, provide intervention activities for increasing activity and healthy eating choices, and conduct a final assessment to determine changes in activity and eating behaviors.

The formative assessment and development of a revised ICDI healthy eating module consisted of four steps: focus groups with students, key informant interviews with community partners, expert panel round table, and expert panel review of materials. An initial draft of revised content was developed by ICDI faculty after the focus groups and key informant interviews, and was revised after the expert round table and post final expert review of materials. The UAB Institutional Review Board (IRB) approved this study.

\section{Focus Groups}

Focus groups were conducted with students who completed the ICDI program in the 2015 cohort. To decrease potential bias, a faculty member and research assistant within the institution with expertise in qualitative methodology and no involvement in the ICDI program conducted all focus groups. All participants completed written informed consent prior to participation. Faculty applied purposeful sampling to recruit students to participate in one of two focus groups. Using a criterion sampling strategy, focus group facilitators specifically sent recruitment emails to all occupational therapy, physical therapy and human studies students who had participated in the ICDI program that academic year. With input from the ICDI faculty, the focus group facilitators developed an interview script with semi-structured questions to explore student perspectives of the ICDI program. To allow students the opportunity to think deeply about their responses, the questions were provided to students one week prior to the focus group. The facilitators scheduled two 60-minute focus groups on campus outside of scheduled class times. Two students expressed a desire to participate but were unable to attend either focus group. These students submitted responses via email. Evaluators considered these responses individual transcripts for data analysis procedures.

Each focus group was audio recorded and transcribed verbatim for data analysis. Faculty used thematic analysis to code transcripts and applied analyst triangulation to enhance credibility of the results. The focus group facilitators who collected the data first coded the transcripts independently and then met to compare and contrast results and identify emerging themes. To ensure rigor, we applied Braun and Clarke's stages of thematic analysis (Braun \& Clarke, 2006). Using this process, we first organized question responses, immersing ourselves in the data reading each transcript multiple times. Next, we generated preliminary codes by chunking together meaningful data ascertaining the key concepts which would later be formed into themes. We then arranged, combined and split our preliminary key concepts to develop overarching themes. 


\section{Key Informant Interviews}

Faculty contacted the primary ICDI site coordinators at each of the three community partner sites via email with an invitation to participate in an interview. With ICDI faculty help, the interviewers developed an interview script containing semi-structured questions to learn the site coordinators' perspectives of the ICDI program. They provided these scripts to each key informant prior to the scheduled interview date. The interviewers scheduled 60-minute interviews at a time and place convenient to the participants. For community partners with multiple coordinators, evaluators conducted these interviews in a small group. Each key informant interview was audio recorded and transcribed verbatim for data analysis. Thematic analysis was used to code the transcripts using the same methodology as the focus groups. IRB approval was obtained prior to the interviews, but the IRB waived consent of key informant interview participants.

\section{Expert Panel Round Table}

Based on the results of focus groups and key informant interviews, ICDI faculty drafted an initial outline for the revised healthy eating module. A round table discussion of experts in nutrition and disability was conducted to gain expert opinion on the draft. Participants included faculty members from the UAB Department of Nutrition Sciences, representatives from ICDI community partners, and faculty members from the UAB Department of Human Studies who specialized in disability and health promotion among individuals with disability. Nominal group technique (NGT; Agency for Healthcare Research and Quality, 2015; Center for Rural Studies, 1998) was used to facilitate the meeting. Nominal group technique is a structured method of group discussion that is structured in a way to ensure all participants' opinions are heard. The group consolidates duplicate ideas and prioritizes individual responses to reach consensus.

Participants were divided into groups of 3-4 participants. Each group addressed five topics: 1. Goals and content of the healthy eating educational session, 2. Educational resources and supplemental tools, 3. Healthy eating assessment resources, 4. Strategies for environmental and institutional change, and 5. Dietetic intern consultations. For each topic, participants were given background information including a review of previously used educational materials provided to students, and feedback from focus groups. Each group reviewed the draft of the revised content for each topic. Small group discussions were then initiated with two prompts: "What is your reaction to the proposed content for this topic?" and "What else should be considered for this resource component?" Participants within each small group took turns giving feedback, which was listed on a board by group facilitators. Once all groups completed discussion, the larger group reconvened to review all responses. A research assistant transcribed all small group responses and took notes on large group discussion.

\section{Expert Review of Materials}

Based on the feedback from the round table discussions, ICDI faculty created the revised healthy eating educational session, and refined the toolkit resources. Once all toolkit resources were compiled, a faculty member in the UAB Department of Nutrition Sciences reviewed the final list of resources for further refinement. 


\section{Pilot Testing}

The revised healthy eating module, consisting of a healthy eating educational session and resource toolkit, was implemented as part of the UAB ICDI program during the fall 2016 semester. All participating students were asked to complete a brief questionnaire at the completion of the program. Questions related to six specific areas of the module: 1.Healthy eating educational session, 2 . Healthy eating patterns assessment tools, 3 . Physical measures assessment tools, 4 . Scales for measuring healthy eating beliefs, 5 . Educational and support tools, and 6. Dietetic intern consultation. For each area, students were asked how much they used each resource and how helpful each resource was. Responses were recorded on a Likert scale of 1-5, with anchors of 1 : "Did not use/participate," and 5: "Used and fully engaged with the material" (use of materials), and 1: "Not helpful" and 5: "Very helpful" (helpfulness of materials). Descriptive statistics (percentages, median, range) were calculated for each Likert scale question. Differences between perceived helpfulness based on reported use of each component was explored using Mann-Whitney U tests.

\section{RESULTS}

\section{Focus Groups and Key Informant Interviews}

Two focus groups with a total of nine students were conducted. Two additional students who were unable to attend provided responses via email. Key informant interviews were conducted with staff from each of the three community sites ( $n=4$ total participants). Four themes emerged. Two themes were unique to the student respondents, and two themes emerged across both groups.

Preparation. Both students and site staff reported that mentor groups seemed to focus on physical activity over healthy eating. While the site staff did not note an apparent reason for this, many students reported that they did not feel prepared to address healthy eating with mentees, noting that their academic preparation (i.e. MSOT program, DPT program, exercise science program) did not include any training on nutrition counseling. For example, one student noted, "all of the professions doing the project [ICDI] don't know much about nutrition interventions." Additionally, participants noted that educational resources for promoting healthy eating that were provided as part of the ICDI program were superficial and needed to be expanded.

Scope of practice. Some students also noted that addressing nutrition was "outside the scope of practice," or "not within the domain" of OT and PT. Students also suggested that the inclusion of students from the UAB nutrition sciences programs might offer additional benefit to the program participants and reduce the stress students experienced in offering advice on healthy eating patterns.

Environmental influences. One theme that emerged in both the student focus groups and site staff interviews was the impact of environmental influences on the mentor groups' ability to impact behavior change. Students noted that more information was needed about the mentees' environment for healthy eating. Specifically, they reported not having adequate information about existing nutrition education within the community 
agencies, inadequate information on the level of influence mentees have on food choices, and not having adequate training on how to intervene on healthy eating when mentees had little to no choice on food. Site staff noted that student mentors seemed primarily focused on individual-level intervention activities and overlooked the environmental contexts that impact mentees' behaviors (e.g. living in a group home setting where they have little input on food provided). Specifically, two sites noted specific environmental aspects of healthy eating that would be of particular benefit to their mentees (an on-site kitchen and vending machine/snack choices), but noted that these were not explored by student mentors.

Sustainability. Sustainability was the second theme that emerged across both groups. Students reported a need to have more communication with caregivers to facilitate sustainable behavior change between mentoring sessions and after the program ended. Site staff voiced similar concerns, noting that some sustainable changes were seen in mentees continuing to make healthy eating choices after the program ended, including making statements such as, "I brought some fruit today," or "I am drinking water because it is good for me." However, they also stated that increased creativity from student mentor groups when developing sustainability plans for their healthy eating activities could impact long-term behavior. For example, one respondent noted that student mentors could produce videos that mentees could watch with their families, and another described the potential for students to develop communication resources for discussing healthy eating goals with physicians and other members of mentees' healthcare teams.

\section{Expert Panel Roundtable}

Based on the results of the student focus groups and key informant interviews, the ICDI faculty created the revised healthy eating educational session, and refined the toolkit resources prior to conducting the expert panel roundtable. Roundtable discussion focused on the revised materials. Seven experts participated in the expert panel roundtable. The most prominent themes that emerged, as well as the decisions reached for addressing each theme are presented in Table 1.

Although participants noted it was important for students to assess environmental barriers while developing the healthy eating plan, the group consensus was that it was outside the scope of the current project to offer environmental intervention. For example, many of the mentees eat lunch provided by the community partners. While mentor groups need to assess the content of these meals as a barrier or facilitator to the mentee's healthy eating plan, it is not realistic to ask the mentors to address unhealthy foods provided in these meals with the community partner. Ideas were discussed for increasing the role of the UAB ICDI program in providing agency-wide interventions such as staff training in the future, but all participants agreed this would take additional time and resources outside the scope of the current project. 
Table 1

Expert Roundtable Discussion Themes and Decisions Reached

\begin{tabular}{|c|c|c|}
\hline Expert Roundtable Theme & $\begin{array}{l}\text { Decisions Reached to } \\
\text { Address Theme }\end{array}$ & $\begin{array}{c}\text { Focus Group/ } \\
\text { Key Informant } \\
\text { Interview Concern } \\
\text { Addressed }\end{array}$ \\
\hline $\begin{array}{l}\text { Healthy eating terminology } \\
\text { - Essential elements required } \\
\text { in the new module: } \\
\circ \text { Clarify giving advice } \\
\text { on "healthy eating } \\
\text { patterns" versus } \\
\text { "nutritional } \\
\text { counseling." } \\
\circ \text { Frame the mentors' } \\
\text { role as promoting } \\
\text { healthy eating } \\
\text { patterns. } \\
\text { Educate students on } \\
\text { the expectations of } \\
\text { this duty within the } \\
\text { context of their } \\
\text { practice areas. }\end{array}$ & $\begin{array}{l}\text { - Use "healthy eating" and } \\
\text { "eating pattern" } \\
\text { terminology instead of } \\
\text { "nutrition" and "diet" to } \\
\text { clearly define students' } \\
\text { role. } \\
\text { - Provide resources for } \\
\text { identifying when it is } \\
\text { appropriate to refer for } \\
\text { nutrition consultation by a } \\
\text { registered dietician. }\end{array}$ & 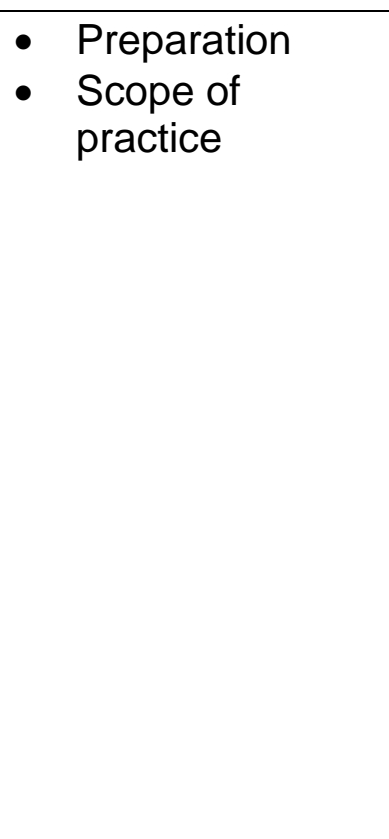 \\
\hline $\begin{array}{l}\text { Flexible strategies for } \\
\text { intervention } \\
\text { - Essential elements required } \\
\text { in the new module: } \\
\circ \text { Educate students on } \\
\text { strategies that can be } \\
\text { applied across } \\
\text { multiple settings (i.e. } \\
\text { schools, institutions, } \\
\text { group homes, family } \\
\text { homes and } \\
\text { independent living). } \\
\text { Include training on } \\
\text { typical facilitators and } \\
\text { barriers to healthy } \\
\text { eating within various } \\
\text { settings. }\end{array}$ & $\begin{array}{l}\text { Provide assessment } \\
\text { resources for individual } \\
\text { and environmental } \\
\text { barriers and facilitators. } \\
\text { - Provide general } \\
\text { strategies that can be } \\
\text { used across settings and } \\
\text { help students understand } \\
\text { site-specific adaptations } \\
\text { (e.g. have teacher or } \\
\text { parent complete food } \\
\text { record on a publically- } \\
\text { available web-based food } \\
\text { tracker like } \\
\text { choosemyplate.gov). }\end{array}$ & $\begin{array}{ll}\text { - } & \text { Preparation } \\
\text { - Environmental } \\
\text { influences }\end{array}$ \\
\hline
\end{tabular}




\begin{tabular}{|c|c|c|}
\hline $\begin{array}{l}\text { Toolkit content and formatting } \\
\text { - Essential elements required } \\
\text { in the new module: } \\
\circ \text { Provide healthy eating } \\
\text { content specific to } \\
\text { community site } \\
\text { participant } \\
\text { characteristics. } \\
\text { Content should be } \\
\text { organized to facilitate } \\
\text { easy use. }\end{array}$ & $\begin{array}{l}\text { - Areas of content to } \\
\text { include: } \\
\text { o General } \\
\text { recommendations } \\
\text { for healthy eating } \\
\text { (i.e. identifying } \\
\text { whole grains, } \\
\text { increasing fruits } \\
\text { and vegetable). } \\
\text { Eating healthy on } \\
\text { a budget. } \\
\text { Recipe and snack } \\
\text { ideas } \\
\text { o Self-monitoring } \\
\text { - Organize resource } \\
\text { content by topic area. } \\
\text { - Present all text in lists } \\
\text { rather than paragraphs. } \\
\text { Provide web-based } \\
\text { resources as hyperlinks } \\
\text { to specific pages within } \\
\text { recommended websites } \\
\text { to minimize within-site } \\
\text { navigation. }\end{array}$ & $\begin{array}{l}\text { - Preparation } \\
\text { - Scope of } \\
\text { practice }\end{array}$ \\
\hline $\begin{array}{l}\text { Addition of students from } \\
\text { Department of Nutrition } \\
\text { Sciences } \\
\text { - Essential elements required } \\
\text { in the new module } \\
\circ \text { Involve students } \\
\text { from the UAB } \\
\text { nutrition sciences } \\
\text { program to add to } \\
\text { both the student } \\
\text { and mentee } \\
\text { experience. }\end{array}$ & $\begin{array}{l}\text { Each mentor group will } \\
\text { complete two web-based } \\
\text { consultations over the } \\
\text { course of the ICDI } \\
\text { program. } \\
\text { - Dietetic interns to provide } \\
\text { feedback on students' } \\
\text { assessment and } \\
\text { intervention strategies for } \\
\text { promoting healthy eating. }\end{array}$ & $\begin{array}{ll}\text { - } & \text { Scope of } \\
\text { practice } \\
\text { - } & \text { Sustainability }\end{array}$ \\
\hline
\end{tabular}

\section{Final Healthy Eating Module}

The final content of the revised UAB ICDI Healthy Eating module is shown in Table 2. All students were required to complete the healthy eating educational session, which consisted of a narrated slide presentation, and take a brief pre-test and post-test to assess basic understanding of the module. Within this educational session, students were referred to the toolkit resources and encouraged to use the resources throughout the program. Each group was also required to complete two dietetic intern consultations as graded activities within the ICDI program. 
Table 2

Final Content of ICDI Healthy Eating Module

\begin{tabular}{|c|c|c|}
\hline Component & Main Topics & Example of Resource \\
\hline $\begin{array}{l}\text { Healthy eating } \\
\text { educational session }\end{array}$ & $\begin{array}{l}\text { - Healthy eating basics } \\
\text { - Assessment of healthy eating } \\
\text { - Promoting healthy eating } \\
\text { behavior } \\
\text { - Recognizing when a healthy } \\
\text { eating referral is needed }\end{array}$ & NA \\
\hline $\begin{array}{l}\text { Dietetic intern } \\
\text { consultation }\end{array}$ & $\begin{array}{l}\text { Consultation with dietetic intern } \\
\text { on } \\
\text { ideas for healthy eating activities } \\
\text { including a guided discussion of: } \\
\text { - Demographics } \\
\text { - Anthropometrics } \\
\text { - Diet-specific concerns } \\
\text { (chewing, allergies) } \\
\text { - Cognitive and communication } \\
\text { - Bkills } \\
\text { - Environmental factors }\end{array}$ & NA \\
\hline \multicolumn{3}{|l|}{ Healthy Eating Toolkit } \\
\hline $\begin{array}{l}\text { Healthy eating } \\
\text { patterns } \\
\text { assessment tools }\end{array}$ & $\begin{array}{l}\text { Surveys and counseling tools to } \\
\text { assess healthy eating habits }\end{array}$ & $\begin{array}{ll}\text { - } & \text { Rate your plate } \\
\text { scale } \\
\text { - } \\
\text { Rapid Eating } \\
\text { Assessment for } \\
\text { Patients (REAP) } \\
\text { scale }\end{array}$ \\
\hline $\begin{array}{l}\text { Physical measures } \\
\text { tools }\end{array}$ & $\begin{array}{l}\text { Instruction on assessing } \\
\text { anthropometric data }\end{array}$ & $\begin{array}{ll}\text { - } & \text { BMI calculator } \\
\text { - Waist circumference } \\
\text { protocol }\end{array}$ \\
\hline $\begin{array}{l}\text { Scales for } \\
\text { measuring } \\
\text { healthy eating } \\
\text { beliefs }\end{array}$ & $\begin{array}{l}\text { Surveys for assessing self- } \\
\text { efficacy and barriers to healthy } \\
\text { eating }\end{array}$ & $\begin{array}{l}\text { - Self-efficacy scale } \\
\text { for healthy eating }\end{array}$ \\
\hline $\begin{array}{l}\text { Educational and } \\
\text { support tools }\end{array}$ & $\begin{array}{l}\text { Web resources for healthy eating } \\
\text { activities and recommendations }\end{array}$ & $\begin{array}{ll}\text { - } & \text { My Plate } \\
\text { (choosemyplate.gov } \\
\text { USDA) } \\
\text { - National Center on } \\
\text { Healthy, Physical } \\
\text { Activity and } \\
\text { Disability } \\
\text { (nchpad.org) }\end{array}$ \\
\hline
\end{tabular}




\section{Pilot Test}

A total of $n=117$ students completed the post-program surveys (response rate $92 \%$ ). When asked how much students used each portion of the Healthy Eating module, the median response ranged from 3 to 4 (range of 1-5 on all components; see Table 3). Rankings of helpfulness ranged from 1 to 5 , with a median of 3 for all components. Given the wide range of scores, rankings of helpfulness were further analyzed based on use of the material. Rankings of 1-3 on use of resources were categorized as low use, and rankings of 4-5 were categorized as high use. Mann-Whitney $U$ tests indicated that students who reported high use of materials found the resources significantly more helpful than those students who reported low use $(p<.001$ for all components; see Table 3). This was true for all components of the module.

Table 3

Student Perceptions of Healthy Eating Module ( $n=117)$

\begin{tabular}{|c|c|c|c|c|}
\hline $\begin{array}{l}\text { Healthy Eating } \\
\text { Module Component }\end{array}$ & $\begin{array}{l}\text { How much did } \\
\text { you use this } \\
\text { resource? } \\
\text { Median (range) }\end{array}$ & $\begin{array}{l}\text { How helpful was } \\
\text { this resource?++ } \\
\text { Median (range) }\end{array}$ & \multicolumn{2}{|c|}{$\begin{array}{c}\text { Helpfulness } \\
\text { based on use } \\
\% \text { of respondents } \\
\text { Median (range) }\end{array}$} \\
\hline Educational session & $4(1-5)$ & $3(1-5)$ & $\begin{array}{c}\text { High use } \\
53.8 \% \\
4(2-5)\end{array}$ & $\begin{array}{c}\text { Low use } \\
46.2 \% \\
3(1-4)^{\star *}\end{array}$ \\
\hline $\begin{array}{l}\text { Dietetic intern } \\
\text { consultation }\end{array}$ & $4(1-5)$ & $3(1-5)$ & $\begin{array}{c}53 \% \\
4(1-5)\end{array}$ & $\begin{array}{c}47 \% \\
2(1-4)^{\star *}\end{array}$ \\
\hline $\begin{array}{l}\text { Healthy eating } \\
\text { patterns } \\
\text { assessments }\end{array}$ & $3(1-5)$ & $3(1-5)$ & $\begin{array}{l}41.4 \% \\
4(2-5)\end{array}$ & $\begin{array}{c}58.6 \% \\
3(1-4)^{\star *}\end{array}$ \\
\hline $\begin{array}{l}\text { Physical measures } \\
\text { tools }\end{array}$ & $3(1-5)$ & $3(1-5)$ & $\begin{array}{l}40.2 \% \\
4(3-5)\end{array}$ & $\begin{array}{c}59.8 \% \\
3(1-5)^{\star *}\end{array}$ \\
\hline $\begin{array}{l}\text { Scales for measuring } \\
\text { healthy eating beliefs }\end{array}$ & $3(1-5)$ & $3(1-5)$ & $\begin{array}{l}36.8 \% \\
4(2-5)\end{array}$ & $\begin{array}{c}63.2 \% \\
3(1-4)^{\star *}\end{array}$ \\
\hline $\begin{array}{l}\text { Educational and } \\
\text { support tools }\end{array}$ & $3(1-5)$ & $3(1-5)$ & $\begin{array}{l}31.6 \% \\
4(3-5)\end{array}$ & $\begin{array}{c}68.4 \% \\
3(1-5)^{\star *}\end{array}$ \\
\hline $\begin{array}{l}\text { +Likert scale respons } \\
5=\text { Used and fully en } \\
\\
{ }^{++} \text {Likert scale respon } \\
{ }^{* *} \mathrm{p}<.001\end{array}$ & Not helpful, & $e, 3=$ Used & $\mathrm{dnot} f u$ & ngage, \\
\hline
\end{tabular}




\section{DISCUSSION}

Promotion of healthy lifestyle behaviors has emerged as a requirement for rehabilitation professionals including occupational and physical therapists, and entry-level education programs must develop curriculum content to prepare students to adequately address these areas of practice. The purpose of this report was to describe the development of content directly related to promotion of healthy eating behaviors. Faculty performed both formative (e.g., focus groups, key informant interviews, nominal group technique, and expert check) and process evaluation (e.g., pilot testing) techniques to assess the need for, revision of, and initial implementation of a healthy eating module. To our knowledge, this is the first exploration of student perception of OT and PT roles of health promotion specifically related to diet behaviors. While a number of studies have explored practitioner perspectives, this evaluation report offers a unique perspective on student perspectives, as well as how curricula might address student self-efficacy related to providing health promotion services within the context of an entry-level generalist practice.

Formative evaluations revealed two primary reasons why students were not regularly addressing nutrition with their mentees. First, many students reported their academic training did not prepare them to discuss eating behaviors with mentees. Second, some felt that discussing nutrition or eating habits was outside the scope of OT or PT practice. This was due, in part, to a belief that they needed to be counseling their patients concerning daily macronutrient and micronutrient intake instead of healthy eating patterns. Snodgrass et al. (2016) reported that allied health professionals including OT, PT, and exercise science practitioners were more likely to engage clients in discussions about heathy eating when they received education about this in their entry-level training programs. This highlights an opportunity to overcome the perceived challenges noted by our students by providing education on the relevant scope of practice and increasing self-efficacy to provide healthy eating information to future patients.

To address these issues in the new healthy eating module, we intentionally used "healthy eating" or "eating patterns" instead of "nutrition" and "diet" in all materials. We also selected screening and intervention materials for the Healthy Eating Toolkit that address eating patterns rather than specific nutrient intake. This change was supported by our experts during the expert panel round table. It is also in line with the Dietary Guidelines for Americans and the Academy of Nutrition and Dietetics, which both encourage healthcare providers to focus on healthy eating patterns when counseling clients/patients about healthy eating rather than focusing solely on a food group (US Department of Health and Human Services, 2015). In addition to focusing on healthy eating patterns, we also included a consultation with a dietetic intern to fine-tune the mentors' recommendations to their mentees as suggested by focus groups and expert panels. This activity was intended to boost students' confidence when counselling their mentees. Additionally, this consultation activity directly addresses requirements from OT and PT accrediting bodies that students learn to effectively consult with other health professionals by allowing students to actively practice this skill (ACOTE, 2018; CAPTE, 2016). 
Pilot test results from the first implementation of the new Healthy Eating module indicated that those students who used the toolkit and fully engaged in the educational modules found these resources helpful. However, only $53 \%$ of students reported high use/engagement in the educational session and dietetic intern consultations, and less than half reported high use/engagement of the toolkit resources. This finding suggests that the faculty need to implement strategies to increase use of these materials by all students. One reason for the lower engagement with toolkit resources may have been that the educational session and consultation were required content of the course with corresponding graded assignments, whereas the toolkit consisted of resources recommended for use, but no required or graded activities were associated with the use of the resources. Inclusion of the toolkit resources in graded activities may further increase engagement. Additionally, faculty have noted a need to increase their reference to these materials during ICDI sessions, encouraging students to utilize the resources while planning weekly mentoring sessions.

\section{Limitations}

This program evaluation had two notable limitations. First, the cross-sectional design of the pilot trial did not allow for assessment of changes over time. Assessing perceived helpfulness of resources before students began interacting with their ICDI mentees and again after would allow us to more fully understand how helpful the resources were in implementation of the mentoring plan. Secondly, future evaluation should include objective markers of students' knowledge of healthy eating, as well as assessments of attitudes and beliefs regarding the role of OT and PT in addressing eating patterns, and level of comfort with addressing these issues, both before and after interacting with the healthy eating module resources. This would allow for assessment of changes in student data over time rather than only assessing student perceptions of materials. Additionally, health promotion curriculum for healthcare providers should not be limited only to content, but also to communication and counseling skills needed to address lifestyle behavior (Bezner, 2015; Richard, Ferguson, Lara, Leonard, \& Younis, 2014). Equipping students with the nutrition knowledge needed to recommend lifestyle change is the first step, but providing them the skills to be comfortable having conversations related to potentially sensitive topics such as weight and personal habits is also needed. The OT and PT curricula at UAB both include coursework on communication and interview skills, but a more direct line of instruction on communication skills for changing lifestyle behaviors may further strengthen the healthy eating toolkit developed in this program.

\section{Future Research}

Multi-step evaluation involving multiple stakeholders guided the development of the new ICDI healthy eating module. We will continue to revise this module and the implementation methods to directly address low engagement rates indicated by the pilot study. Because students who reported full use/engagement of the new module found the resources helpful when counseling their mentees about healthy eating, the next step in the revision process will focus on strategies to increase student exposure to this material. Continual evaluation to ensure that students feel comfortable in promoting healthy eating is important not only to meet accreditation standards but is also needed 
to meet governmental and professional organizations' calls for OTs and PTs to incorporate health promotion in typical care. We will also continue to track student engagement with the new healthy eating module, as well as the impact of the module on student learning outcomes overtime.

\section{Implications for Occupational Therapy Education}

Training entry-level OTs to provide health promotion activities related to all health behaviors including healthy eating is vital for preparing them to address the current healthcare needs of the US population. Development of innovative educational methods are needed to increase awareness of the role of OT in addressing healthy eating patterns, and to prepare entry-level practitioners to feel competent to fulfill this role.

While we incorporated the healthy eating content into a second year course of an MSOT program, this content could also be included earlier in the course sequencing. Introducing health promotion activities early in entry-level curricula may lay the foundation for students valuing these activities within the scope of practice of OT. Additionally, we believe that part of the success of the healthy eating module developed in this report came from the fact that it was enacted as part of an interdisciplinary service learning project. Allowing students to apply the concepts of healthy eating within a service learning environment such as the ICDI program may lead to a greater understanding and appreciation for the role of OT in these interventions. This model could also be expanded for inclusion in fieldwork, where students are able to apply concepts of health promotion for healthy eating learned in a classroom setting in a real world clinical environment.

\section{CONCLUSION}

Health promotion of all lifestyle behaviors, including healthy eating, is an increasing part of clinical practice for occupational therapists. Incorporating training and practice activities for promotion of healthy eating in entry level OT coursework may increase the comfort of future OTs in providing these interventions. The healthy eating module developed for the UAB ICDI program is a novel, interactive method of providing this content, and pilot test results indicated that those students who engaged with the module content found it helpful for increasing their understanding of how to help mentees within the ICDI program improve healthy eating.

\section{References}

Accreditation Council for Occupational Therapy Education (2018). Standards and Interpretive Guide. Retrieved from:

https://www.aota.org/ /media/Corporate/Files/EducationCareers/Accredit/Standa rdsReview/2018-ACOTE-Standards-Interpretive-Guide.pdf

Agency for Healthcare Research and Quality (2015). Nominal Group Technique. Retrieved from: https://healthit.ahrq.gov/health-it-tools-and-resources/evaluationresources/workflow-assessment-health-it-toolkit/all-workflow-tools/nominalgroup-technique 
American Physical Therapy Association (2015). The Association's role in advocacy for prevention, wellness, fitness, health promotion and management of disease and disability. HOD P06-15-23-15.

Bezner, J.R. (2015). Promoting health and wellness: Implications for physical therapist practice. Physical Therapy, 95(10),1433-1444. https://doi.org/10.2522/pti.20140271.cx

Braun, V., \& Clarke, V. (2006). Using thematic analysis in psychology. Qualitative Research in Psychology, 3(2), 77-101. https://doi.org/10.1191/1478088706qp063oa

Centers for Disease Control and Prevention (2002). State-specific prevalence of obesity among adults with disabilities--eight states and the District of Columbia, 19981999. MMWR Morbidty and Mortality Weekly Report, 51(36), 805-808.

Center for Rural Studies (1998). Guidelines for using the nominal group technique. Retrieved from: https://www.uvm.edu/crs/resources/nerl/group/a/meet/Exercise7/b.html

Commission on Accredidation in Physical Therapy Education (2016). PT Standards and Required Elements. Retrieved from: http://www.capteonline.org/AccreditationHandbook/

Jackson, E.A., Krishnan, S., Meccone, N., Ockene, I.S., \& Rubenfire, M. (2010). Perceived quality of care and lifestyle counseling among patients with heart disease. Clinical Cardiology, 33(12),765-769. https://doi.org/10.1002/clc.20839

Jensen, M.D., Ryan, D.H., Apovian, C.M., Ard, J.D., Comuzzie, A.G., Donata, K.A.,...Tomaselli, G.F. (2014). 2013 AHA/ACC/TOS guideline for the management of overweight and pbesity in adults: A report of the American College of Cardiology/American Heart Association Task Force on Practice Guidelines and the Obesity Society. Circulation, 129(25 Suppl 2),S102-138. https://doi.org/10.1161/01.cir.0000437739.71477.ee

Kris-Etherton, P.M., Akabas, S.R., Bales, C.W., Bistrian, B., Braun, L., Edwards, M.S.,...Van Horn, L. (2014). The need to advance nutrition education in the training of health care professionals and recommended research to evaluate implementation and effectiveness. American Journal of Clinical Nutrition, 99(5),1153S-1166S. https://doi.org/10.3945/ajcn.113.073502

Lichtenstein, A.H., Appel L.J., Brands M., Carnethon, M., Daniels, S., Franch, H.A.,...Wylie-Rosett, J. (2006). Diet and lifestyle recommendations revision 2006: A scientific statement from the American Heart Association Nutrition Committee. Circulation, 114(1), 82-96. https://doi.org/10.1161/CIRCULATIONAHA.106.176158

Liou, T.H., Pi-Sunyer, F.X., \& Laferrere, B. (2005). Physical activity and disability. Nutrition Reviews, 66 (10), 321-31. https://doi.org/10.1111/j.1753-4887.2005.tb00110.x

Pool, A.C., Kraschnewski, J.L., Cover, L.A., Lehman, E.B., Stuckey, H.L., Hwang, K.O.,...Sciamanna, C.N. (2014). The impact of physician weight discussion on weight loss in US adults. Obesity Research \& Clinical Practice, 8(2), e131-139. https://doi.org/10.1016/j.orcp.2013.03.003 
Richard, P., Ferguson, C., Lara, A.S., Leonard, J., \& Younis, M. (2014). Disparities in physician-patient communication by obesity status. Inquiry: A Journal of Medical Care Organization, Provision and Financing, 51, 0046958014557012. https://doi.org/10.1177/0046958014557012

Rose, S.A., Poynter, P.S., Anderson, J.W., Noar, S.M., \& Conigliaro, J. (2013). Physician weight loss advice and patient weight loss behavior change: A literature review and meta-analysis of survey data. International Journal of Obesity, 37(1),118-128. https://doi.org/10.1038/ijo.2012.24

Scaffa, M.E., Van Slyke, N., \& Brownson, C.A. (2008). Occupational therapy services in the promotion of health and the prevention of disease and disability. American Journal of Occupational Therapy, 62(6), 694-703. https://doi.org/10.5014/ajot.62.6.694

Snodgrass, S.J., Guest, M., Kable, A.K., James, C., Ashby, S.E., Plotnikoff, R.C., \& Collins, C.E. (2016). Weight management advice for clients with overweight and obesity: Allied health professional survey. Healthcare, 4(4), E85. https://doi.org/10.3390/healthcare4040085

US Department of Health and Human Services. (2013a). I Can Do It, You Can Do It. Retreived from www.fitness.gov/participate-in-programs/i-can-do-it-you-can-do-it.

US Department of Health and Human Services. (2013b). I Can Do It, You Can Do It: Motivating Individauls with Disabilites to Lead Healthy, Active Lifestyles: Program Manual. President's Council on Fitness, Sports and Nutrition.

US Department of Health and Human Services and U.S. Department of Agriculture. (2015). 2015-2020 Dietary Guidelines for Americans. 8th Edition. Retrieved from http://health.gov/dietaryguidelines/2015/guidelines/.

Walkeden, S., \& Walker, K.M. (2015). Perceptions of physiotherapists about their role in health promotion at an acute hospital: A qualitative study. Physiotherapy, 101(2), 226-231. https://doi.org/10.1016/i.physio.2014.06.005

Weil, E., Wachterman, M., McCarthy, E.P., Davis, R.B., O'Day, B., lezzoni, L.I., \& Wee, C.C., (2002). Obesity among adults with disabling conditions. JAMA, 288(10), 1265-1268. https://doi.org/10.1001/jama.288.10.1265

Wingo, B.C., Lein, D.H., Barstow, B., Eidson, C.A., Pearce, T.S., Malone, L., \& Morris, D.M. (2019). Preparing entry-level occupational therapy and physical therapy students to promote health and wellbeing with individuals with disabilities. Journal of Occupational Therapy Education, 3(1). Retrieved from https://encompass.eku.edu/jote/ 